\title{
Pesticidal Activity of Sundarban Mangrove Plant Extracts against Sitophilus Pests and Identification of Active Constituents Using LC-MS
}

\author{
Md. Abdur Rahman, ${ }^{1}$ Rinku Rani Paul, ${ }^{1}$ Chaina Biswas, ${ }^{1}$ Hakima Akter, ${ }^{1}$ Razina Rouf, \\ Sushmita Nath, ${ }^{3}$ Jamil A. Shilpi ${ }^{1},{ }^{1}$ Lutfun Nahar, ${ }^{4}$ Stayajit D. Sarker, ${ }^{3}$ \\ and Shaikh Jamal Uddin $\mathbb{D}^{1}$ \\ ${ }^{1}$ Pharmacy Discipline, Life Science School, Khulna University, Khulna 9208, Bangladesh \\ ${ }^{2}$ Department of Pharmacy, Faculty of Life Science, Bangabandhu Sheikh Mujibur Rahman Science and Technology University, \\ Gopalganj 8100, Bangladesh \\ ${ }^{3}$ Centre for Natural Products Discovery, School of Pharmacy and Biomolecular Sciences, Liverpool John Moores University, \\ James Parsons Building, Byrom Street, Liverpool L3 3AF, UK \\ ${ }^{4}$ Laboratory of Growth Regulators, Institute of Experimental Botany ASCR \& Palacký University, Olomouc, Czech Republic
}

Correspondence should be addressed to Shaikh Jamal Uddin; uddinsj@yahoo.com

Received 5 July 2021; Revised 2 November 2021; Accepted 23 November 2021; Published 15 December 2021

Academic Editor: Mounir Tilaoui

Copyright (C) $2021 \mathrm{Md}$. Abdur Rahman et al. This is an open access article distributed under the Creative Commons Attribution License, which permits unrestricted use, distribution, and reproduction in any medium, provided the original work is properly cited.

\begin{abstract}
Plants act as a rich source of novel natural pesticides. In the backdrop of the recent revival of interest in developing plant-based insecticides, this study was carried out to investigate the pesticidal activity of Sundarban mangrove plants. A total of nine different plant parts from five plants, namely, Aegiceras corniculatum, Excoecaria agallocha, Heritiera fomes, Xylocarpus moluccensis, and Xylocarpus granatum, were extracted with methanol and tested for insecticidal activity against two common stored product pests Sitophilus oryzae and Sitophilus zeamais using direct contact feeding deterrent wafer disc method. Three bark extracts from A. corniculatum, E. agallocha, and H. fomes showed potent and statistically significant insecticidal activity against both $S$. oryzae and S. zeamais pests ( $80-100 \%$ mortality). All the active bark extracts were further fractionated using C-18 solid-phase extraction (SPE) columns and tested for their insecticidal activity against $S$. oryzae pest to identify the active fraction. Only the SPE4 fraction $(100 \% \mathrm{MeOH})$ from all the three active plants showed the activity against S. oryzae pest with a lethal concentration $50 \%\left(\mathrm{LC}_{50}\right)$ value of $0.5,1.0$, and $1.5 \mathrm{mg} /$ disc for A. corniculatum, E. agallocha, and $H$. fomes, respectively. The active fraction of $A$. corniculatum was further profiled for identification of active compounds using LC-ESI-MS and identified (along with some unknown peaks) two previously reported compounds at $\mathrm{m} / z 625.17630$ (isorhamnetin 3-Orutinoside) and 422.25346 (paspaline) as major constituents. Insecticidal activities of these plants are reported in this study for the first time and would be useful in promoting research aiming for the development of new biopesticides from mangrove plants.
\end{abstract}

\section{Introduction}

The theme of World Food Day 2018 was "Zero Hunger," and that objective was aimed to be accomplished by 2030. One of the major ways to eliminate world hunger and poverty is to make agriculture more environmentally sustainable. The pest problem is a major constraint for achieving higher production of agricultural crops [1]. About $10-30 \%$ of crops including fruits and vegetables are lost due to pests and associated diseases each year [2-5]. Management of agricultural pests over the past half century has largely depended on the use of synthetic chemical pesticides for field and postharvest protection of crops [6]. Many synthetic pesticides are banned or restricted under international 
agreements. Applied pesticide residues can remain in water, food, fruits, and vegetables [7]. Moreover, they also kill nontarget arthropods and insects involved in pollination. Excess use of synthetic pesticides also led to other problems including developing resistance [8]. Epidemiological studies have found carbamates and organophosphates to be carcinogenic, mutagenic, teratogenic, or allergenic [9]. Longterm residual deposition of these toxic chemicals on vegetables and fruits is likely to create different diseases in humans including cancer, skin diseases, hypertension, and kidney diseases [10]. The incidence of pesticide poisoning has been increasing, and it is estimated that about 5 million people die every year as a result of intentional, accidental, and occupational exposure worldwide [11]. Therefore, there is an urgent need to discover novel natural pesticides that could prevent damage to agricultural crops and are nontoxic to the environment.

Natural pesticides compared to synthetic ones are safer for the environment, relatively nontoxic to health, biodegradable, less expensive, easily processed, and potentially suitable for use in integrated pest management [12]. A number of plants around the world have been used traditionally for their pesticidal activity and act as a rich source of novel natural pesticides [13]. A number of examples of currently used known natural pesticides from plants are pyrethrin and pyrethroids. Neem, another most common example, Azadirachta indica, is presently the most important botanical insecticide in use throughout the world [14]. More than 2,000 different plants are known to have insecticidal properties [15]. Many other plant species have already identified to be used as natural pesticides or insecticide compounds [16-19].

Plants from mangrove and mangrove associates have long been widely used for medicinal and nonmedicinal purposes throughout the world. A literature study proved that extracts from plants of mangrove origin possess bioactivity against humans, animals, and plant pathogens [20]. The diversity in the activity of these plants could be due to the peculiar environment (high moisture, large tidal difference, high salinity, an abundance of living organisms and insects, etc.) in which they exist, producing stressful conditions, which might change their morphology, physiognomy, and biosynthetic pathways to survive [20,21]. Several novel bioactive constituents belonging to diverse chemical classes have been characterized from mangroves, and therefore, they have clinical, toxicological, and economic importance. Bangladesh has the largest single block of the Sundarban mangrove forests in the world, which is a globally significant ecosystem rich in plant biodiversity [20,22]. A total of 245 genera and 334 plant species were recorded in the Sundarban mangrove forests in 1903 [23]. Many of these Sundarban mangrove species including Aegiceras corniculatum, Excoecaria agallocha, Heritiera fomes, Xylocarpus moluccensis, and Xylocarpus granatum have been used in traditional medicines, but the scientific information about the biological effects of these plants and active substances are scarce and poorly documented. These plant extracts have been found to possess different bioactivity and toxicity, and a number of bioactive constituents have also been isolated from plants of mangrove origin (Supplementary Table S1). However, the chemistry, bioactivity, and efficacy of these mangrove plants and their constituents remain underexplored. For the first time, we have screened a total of nine different plant parts from A. corniculatum, E. agallocha, H. fomes, X. moluccensis, and $X$. granatum for insecticidal activity against two common stored product pests $S$. oryzae and S. zeamais and further identified the active constituents present in the active extract.

\section{Materials and Methods}

2.1. Sundarban Plants Collection, Drying, and Extraction. With the help of the Department of Forestry, Khulna, a total of nine plant parts of five (05) Sundarban mangrove plants from four families including Aegiceras corniculatum, Excoecaria agallocha, Heritiera fomes, Xylocarpus moluccensis, and Xylocarpus granatum have been collected from West Sundarban, Kolagachia forest range, Munshiganj, Satkhira $\left(22.2152^{\circ} \mathrm{N}\right.$, $89.2376^{\circ} \mathrm{E}$ ), Bangladesh (Table 1 and Supplementary Figure S1). All the collected plants were identified by Prof. Dr. Md. Azharul Islam, Forestry and Wood Technology Discipline, Khulna University, and immediately air-dried for further extraction. The dried plant parts were grinded into a coarse powder with the help of a suitable grinder. The powders were stored in airtight containers and kept in the cool, dark, and dry place until analysis commenced. About $175 \mathrm{~g}$ of each powdered material was taken in clean, flat-bottomed glass containers, and the material was soaked with $900 \mathrm{ml}$ methanol. The containers with their contents were sealed and kept for a period of 7 days accompanying occasional shaking and stirring. The whole mixture then underwent a coarse filtration by a piece of clean, white cotton. Then, it was filtered through Whatman filter paper. Following the filtration, the solvent was evaporated using rotary evaporation.

2.2. Chemical Reagents and Equipment. All the solvents used for extraction and chromatographic use were analytical grade and HPLC grade from Merck KGaA, Germany. The positive control permethrin was bought from a local supermarket. The solid-phase fractionation was conducted with reverse-phase SPE columns (Alltech, $60 \mathrm{~mL}, 10 \mathrm{~g}$ high capacity $\mathrm{C}_{18}$ ) using Visiprep 12-port vacuum manifold (Sigma-Aldrich, Germany). Chemical profiling of active fraction was analyzed with an Agilent 1260 Infinity II series HPLC system (Agilent Technologies Inc., Santa Clara, CA, USA) combined with Agilent 6530 Accurate-Mass Q-TOF-LC-MS mass spectrometer (Agilent Technologies Inc., Santa Clara, CA, USA). The HPLC system had a binary solvent manager, a column, and a photodiode array detector. The column was a $50 \mathrm{~mm} \times 2.1 \mathrm{~mm}$ i.d., $1.8 \mu \mathrm{m}$, Agilent ZORBAX Eclipse Plus $\mathrm{C}_{18}$ reverse-phase column (Agilent Technologies Inc., Santa Clara, CA, USA).

\subsection{Solid-Phase Fractionation of Active Plant Extracts.} Solid-phase extraction (SPE) is widely employed as an alternative method to liquid-liquid extraction aiming at the 
TABLE 1: List of collected Sundarban plant species for methanol extraction, their traditional uses, part used, and extraction yields [24]].

\begin{tabular}{|c|c|c|c|c|c|}
\hline Plant name & Family & $\begin{array}{l}\text { Local } \\
\text { name }\end{array}$ & Traditional uses & Part used & $\begin{array}{l}\text { Extraction } \\
\text { yield }(\%)^{*}\end{array}$ \\
\hline $\begin{array}{l}\text { Aegiceras corniculatum } \\
\text { (L.) blanco }\end{array}$ & Myrsinaceae & Kholisha & $\begin{array}{l}\text { Rheumatism, painful arthritis, inflammation, and } \\
\text { fish poison }\end{array}$ & Bark & 13.5 \\
\hline Excoecaria agallocha (L.) & Euphorbiaceae & Geoa & $\begin{array}{l}\text { Epilepsy, conjunctivitis, dermatitis, hematuria, } \\
\text { leprosy toothache, and fish poison }\end{array}$ & Bark & 7.2 \\
\hline Heritiera fomes (buch.) & Sterculiaceae & Sundari & $\begin{array}{c}\text { GIT disorders, hepatic disorders, skin diseases, } \\
\text { diabetes, and goiter }\end{array}$ & $\begin{array}{l}\text { Bark } \\
\text { Leaf }\end{array}$ & $\begin{array}{c}8.9 \\
10.2\end{array}$ \\
\hline $\begin{array}{l}\text { Xylocarpus granatum } \\
\text { (K. D. Koenig) }\end{array}$ & Meliaceae & Dhundul & $\begin{array}{l}\text { Antibacterial, malaria, inflammation, dysentery, } \\
\text { diarrhea, cholera, CNS depressant, and anticancer }\end{array}$ & Bark & 17.1 \\
\hline $\begin{array}{l}\text { Xylocarpus moluccensis } \\
\text { (lam.) M. Roem. }\end{array}$ & Meliaceae & Pashur & $\begin{array}{l}\text { Fever, inflammation, dysentery, diarrhea, cholera, } \\
\text { and abdominal problems }\end{array}$ & $\begin{array}{c}\text { Bark } \\
\text { Leaf } \\
\text { Fruit } \\
\text { Pneumatophore }\end{array}$ & $\begin{array}{c}14.1 \\
4.7 \\
13.3 \\
23.2\end{array}$ \\
\hline
\end{tabular}

${ }^{*}$ Extraction yield $(\%)=$ dry weight of methanol extract/dry weight of test plant part) $\mathrm{x} 100$.

separation, purification, and concentration of bioactive compounds. The important application of SPE is the fractionation of the crude extract into different compounds or groups of compounds by eluting the extract with different solvents for further chromatographic separations [24]. The crude active methanolic extracts from A. corniculatum, E. agallocha, and $H$. fomes were fractionated into four fractions using reverse-phase SPE columns (Alltech, $60 \mathrm{~mL}, 10 \mathrm{~g}$ high capacity C18) with a stepwise methanol/water gradient. SPE columns were first preconditioned with 3 bed volumes (BV) of methanol $(180 \mathrm{~mL})$ and then equilibrated using $3 \mathrm{BV}$ of water $(180 \mathrm{~mL})$. A sample of each crude methanolic extract $(500 \mathrm{mg})$ was first dissolved in $1 \mathrm{~mL}$ of methanol and loaded into the SPE column and then fractionated into four fractions by eluting with water/methanol using a stepwise gradient (Supplementary Table S2).

2.4. Insect Tested. Insecticidal activity of collected mangrove plant extracts was tested against stored product insects Sitophilus oryzae and Sitophilus zeamais(family: Dryophthoridae). The pests were collected from the Agrotechnology Discipline, Khulna University, and the culture was maintained in the laboratory on rice grain and red lentil grain, respectively, in plastic containers $(26 \mathrm{~cm} \times 30 \mathrm{~cm} \times 20 \mathrm{~cm})$ at $29 \pm 1{ }^{\circ} \mathrm{C}, 50-60 \%$ r.h., and a 16:8 light:dark cycle photoperiod without exposure to any insecticide.

\subsection{Pesticidal Activity Screening of the Sundarban Plant} Extracts. The insecticidal activity of the Sundarban plant extracts was investigated against two common stored product pests (Sitophilus oryzae and Sitophilus zeamais) as per the methods of Boussaada et al., 2008 and Kim et al., 2003 with some modification [12,25]. Briefly, a dose of $2.5 \mathrm{mg}$ of each plant extract in $400 \mu \mathrm{l} \mathrm{MeOH}$ was applied to wafer discs made of wheat (weight about $30 \mathrm{mg}$ and $1 \mathrm{~cm}$ diameter). Permethrin at $2.0 \mathrm{mg} /$ discs was used as a positive control, and only vehicle $(400 \mu \mathrm{l} \mathrm{MeOH} /$ discs $)$ served as a negative control in the experiment. The discs were left under a fume hood to dry, and then, each disc was weighed before placement in the Petri dish for activity study. After drying, discs were placed in Petri dish ( $9 \mathrm{~cm}$ diameter) and then 10 adults of each either $S$. oryzae or S. zeamais were placed in the Petri dish, which was covered with a lid and kept at $29 \pm 1{ }^{\circ} \mathrm{C}, 50-60 \%$ r.h., and a 16:8 light:dark cycle. Mortalities were determined by the number of dead adults at 5 , 10 , and 15 days after treatment. Test insects were considered dead if appendages did not move when prodded with a fine brush. Three replications were setup for ach assay.

2.6. $L C_{50}$ Determination of Active Fraction. All the fractions were further evaluated for pesticidal activity using the above method against $S$. oryzae pest, and lethal concentration $50 \%$ $\left(\mathrm{LC}_{50}\right)$ of all active fractions was determined by testing each fraction at a dose of 2.5, 2.0, 1.5, 1.0, and $0.5 \mathrm{mg} /$ disc. $\mathrm{LC}_{50}$ was recorded at which concentration $50 \%$ of the pest was died.

2.7. LC-ESI-MS Analysis of A. corniculatum Active Fraction. Chemical profiling of active SPE4 fraction of A. corniculatum was analyzed with an Agilent 1260 Infinity II series HPLC system (Agilent Technologies Inc., Santa Clara, CA, USA) combined with Agilent 6530 AccurateMass Q-TOF-LC-MS mass spectrometer (Agilent Technologies Inc., Santa Clara, CA, USA). The HPLC system had a binary solvent manager, a column, and a photodiode array detector. The column was a $50 \mathrm{~mm} \times 2.1 \mathrm{~mm}$ i.d., $1.8 \mu \mathrm{m}$, Agilent ZORBAX Eclipse Plus $\mathrm{C}_{18}$ reverse-phase column (Agilent Technologies Inc., Santa Clara, CA, USA). Elution was carried out with a binary solvent system consisting of $0.1 \%$ aqueous formic acid $(A)$ and methanol containing $0.1 \%$ formic acid (B) at a constant flow rate of $0.4 \mu \mathrm{L} / \mathrm{min}$. The elusion events were as follows: $0 \mathrm{~min}$ : $5 \% \mathrm{~B} ; 0-7.0 \mathrm{~min}$ : 5-100\% B; 7.0-10.0 min: 100\% B; 10.0-11.0 min: 100-5\% B; and $11.0-13.0 \mathrm{~min}: 5 \% \mathrm{~B}$. UV-Vis $(190-500 \mathrm{~nm})$, and MS data $(\mathrm{m} / z 100$ to 1700$)$ were recorded from 0 to $11 \mathrm{~min}$. The ESI ionization was performed in positive ion mode, and the instrument parameters were as follows: capillary voltage: $2.4 \mathrm{kV}$; desolvation temperature: $650^{\circ} \mathrm{C}$; source temperature: $150^{\circ} \mathrm{C}$; desolvation and cone gas $\left(\mathrm{N}_{2}\right)$ flow rate: 1,000 and $100 \mathrm{Lh}^{-1}$, respectively; and collision gas: argon. 


\section{Results}

3.1. Insecticidal Activity of Collected Sundarban Plant Crude Methanolic extracts. Plant-derived insecticides are commonly pest-specific and are relatively nontoxic to nontarget organisms including humans [26]. A number of mangroves and mangrove associates are used as folklore medicinal, insecticidal, and pesticidal plants [27]. In this study, a total of nine extracts from five Sundarban mangrove plants were investigated for insecticidal activity against two store product pests S. oryzae and S. zeamais that so far not studied before. For the screening of insecticidal activity, all the plant parts were extracted with methanol and Table 1 represents the extraction yields of all collected plants. Extraction yield results demonstrated that $X$. granatum and $X$. moluccensis showed the highest yield indicating a high number of polar constituents in comparison to A. corniculatum, H. fomes, and E. agallocha (Table 1).

Insecticidal activities of crude extracts were tested against two store product pests S. oryzae and S. zeamais. Table 2 demonstrates the toxicity of the methanolic crude extracts against the tested store product pests at $2.5 \mathrm{mg} / \mathrm{disc}$ for 5,10 , and 15 days of treatment. The results demonstrated that the nonselective mortalities were higher in bark extracts of A. corniculatum, E. agallocha, and H. fomes (80-100\% mortality) against both $S$. oryzae and $S$. zeamais pests throughout the treatment period at a dose of $2.5 \mathrm{mg} / \mathrm{disc}$ (Table 2). The methanol extracts of bark and leaf of $X$. moluccensis showed selective insecticidal activity against S. oryzae (50\% mortality) and S. zeamais ( $73 \%$ mortality), respectively, at 15 days of treatment. Other extracts showed low to no insecticidal activity against either of the tested pests. The bark extracts of A. corniculatum, E. agallocha, and $H$. fomes showed over $42 \%$ mortality after the 5 days of treatment, the value increased to over $82-100 \%$ mortality after 15 days of treatment against both the pests, and the data were statistically significant $(P<0.001)$, whereas the standard permethrin showed $80 \%$ to $100 \%$ mortality at 5 th to 15 th days of treatment.

3.2. SPE Fractionation of Active Crude Extracts and Insecticidal Activity of Each Fraction. Primary pesticidal activity results demonstrated that the crude extract of A. corniculatum, E. agallocha, and H. fomes possesses significant pesticidal activity against the tested pests. Solidphase extraction (SPE) is a widely employed fractionation technique aiming at the separation, purification, and concentration of bioactive polar compounds for further chromatographic separations [24]. The active crude methanolic extracts were further fractionated into four fractions (SPE1, SPE2, SPE3, and SPE4) using stepwise gradient methanol/water using C18 cartridge and further tested for pesticidal activity against $S$. oryzae. The results demonstrated that only the SPE4 fraction $(100 \% \mathrm{MeOH})$ for all the tested plant extracts was active against $S$. oryzae at $2.0 \mathrm{mg} / \mathrm{disc}$. Table 3 presents the toxicity results of SPE4 fractions of A. corniculatum, E. agallocha, and $H$. fomes against $S$. oryzae pest. The percentage of mortality of the
SPE4 fraction for A. corniculatum was found the highest $(97 \%)$ at $2.0 \mathrm{mg} / \mathrm{disc}$ among the fractions tested. The other two SPE4 fractions of E. agallocha and $H$. fomes also showed $90 \%$ and $80 \%$ mortality, respectively, after 15 days treatment period (Table 3). The insecticidal effect of A. corniculatum fractions was also prominent after the initial 5 days treatment ( $37 \%$ mortality), and that value was increased to $73 \%$ at 10 days and $97 \%$ at 15 days treatment. All the results were statistically significant. Further $\mathrm{LC}_{50}$ concentration was determined for all of the active SPE4 fractions, and $A$. corniculatum fraction was found the lowest $\mathrm{LC}_{50}(0.5 \mathrm{mg} / \mathrm{disc})$ among all the fractions tested ( LC $_{50}: 1-1.5 \mathrm{mg} / \mathrm{disc}$ ) and was comparable to permethrin $\left(\mathrm{LC}_{50}: 0.4 \mathrm{mg} / \mathrm{disc}\right.$ ) (Table 3 ). This result suggests that the potent pesticide constituents present in the SPE4 fraction of $A$. corniculatum.

3.3. LC-ESI-MS Identification of Active Compounds in A. corniculatum Active Fraction. Plants have the ability to develop different constitutive and inducible mechanisms for the protection from pathogen and herbivores via various secondary chemical compounds or morphological barriers [28]. A number of plant secondary metabolites have also been reported to use for the management of pests [29]. Liquid chromatography coupled to mass spectrometry (LCMS) technique has become more sensitive and specific for the analysis of phytoconstituents. In this study, the most active SPE4 fractions of A. corniculatum were further analyzed by LC-MS using electrospray ionization (ESI) positive ion mode. Chemical constituents reported so far from these plants were matched with the molecular ion $[M+H]^{+}$peaks observed in the mass spectrums (Figures 1 and 2) of SPE4 fraction of A. corniculatum, and the results showed that the active SPE4 fractions of $A$. corniculatum contain different classes of phytoconstituents.

The LC-ESI-MS mass chromatogram of the active SPE4 fraction of A. corniculatum revealed two major peaks. Compound 1 in the SPE4 fraction of A. corniculatum exhibited a base peak $[M+H]^{+}$with $\mathrm{m} / z 625.17598$ at 6.05 min that suggested a molecular formula $\left[\mathrm{C}_{28} \mathrm{H}_{32} \mathrm{O}_{16}\right]$, which confirmed that compound $\mathbf{1}$ was isorhamnetin 3-Orutinoside (flavonol) m.w. 624.16870 previously identified from bark extract of $A$. corniculatum [30] (Figure 1). The identification of compound $\mathbf{1}$ was further confirmed by comparing its mass fragmentation of pseudomolecular ion $\left(\mathrm{m} / z\right.$ at $\left.625[\mathrm{M+H}]^{+}\right)$of isorhamnetin 3-O-rutinoside that resulted in major fragments including a complete loss of disaccharide, rutinose at $m / z 317\left([(M+H)-308]^{+}\right)$, from flavonol rutinosides, which has been previously reported [31] (Figure 1), whereas compound 2 in A. corniculatum fraction appeared as a base peak $\left[M+\mathrm{H}^{+}\right.$with $\mathrm{m} /$ $z 422.25332$ at $7.84 \mathrm{~min}$ that suggested a molecular formula $\left[\mathrm{C}_{28} \mathrm{H}_{39} \mathrm{NO}_{2}\right]$ and confirmed compound 2 as paspaline (indole-diterpenoid) m.w. 421.2460, previously identified from bark extract of A. corniculatum [32] (Figure 2). Paspaline was purified from the endophytic fungus Penicillium sp. that isolated from the mangrove plant Aegiceras corniculatum [33]. 
TABLE 2: Insecticidal activity of the methanolic crude extract of Sundarban plants against S. oryzae and S. zeamais insects at $2.5 \mathrm{mg} /$ disc concentration.

No of dead adult S. oryzae insects No of dead adult S. zeamais insects

Name of plant extract

Plant part ${ }^{¥} \quad$ No. of insect

Days after treatment

Days after treatment

\begin{tabular}{|c|c|c|c|c|c|c|c|c|}
\hline & & & $5^{\text {th }}$ & $5^{\text {th }}$ & $15^{\text {th }}$ & $5^{\text {th }}$ & $5^{\text {th }}$ & $15^{\text {th }}$ \\
\hline A. corniculatum (L.) blanco & $\mathrm{B}$ & 10 & $6.0 \pm 0.6^{*}$ & $8.3 \pm 0.3^{*}$ & $9.6 \pm 0.3^{*}$ & $5.0 \pm 0.5^{*}$ & $6.0 \pm 0.6^{*}$ & $8.3 \pm 0.8^{*}$ \\
\hline E. agallocha $(\mathrm{L})$. & $\mathrm{B}$ & 10 & $7.7 \pm 0.3^{*}$ & $9.0 \pm 0.6^{*}$ & $10 \pm 0.0^{*}$ & $4.3 \pm 0.3^{*}$ & $8.0 \pm 0.5^{*}$ & $9.3 \pm 0.6^{*}$ \\
\hline \multirow{2}{*}{ H. fomes (buch.) } & $\mathrm{B}$ & 10 & $4.6 \pm 0.3^{*}$ & $8.3 \pm 1.6^{*}$ & $10 \pm 0.0^{*}$ & $5.0 \pm 0.6^{*}$ & $6.3 \pm 0.8^{*}$ & $10 \pm 0.0^{*}$ \\
\hline & $\mathrm{L}$ & 10 & $1.3 \pm 0.3$ & $2.3 \pm 0.3$ & $3.6 \pm 0.8^{*}$ & $0.0 \pm 0.0$ & $1.3 \pm 0.33$ & $3.6 \pm 0.3$ \\
\hline \multirow[t]{2}{*}{ X. granatum (K. D. Koenig) } & $\mathrm{B}$ & 10 & $1.0 \pm 0.0$ & $1.3 \pm 0.3$ & $2.0 \pm 0.5$ & $0.0 \pm 0.0$ & $0.33 \pm 0.3$ & $1.3 \pm 0.33$ \\
\hline & $\mathrm{B}$ & 10 & $2.3 \pm 0.3$ & $3.0 \pm 0.5$ & $5.0 \pm 0.6^{*}$ & $0.33 \pm 0.3$ & $1.0 \pm 0.0$ & $1.6 \pm 0.3$ \\
\hline \multirow{3}{*}{ X. moluccensis (lam.) M. Roem. } & $\mathrm{L}$ & 10 & $0.3 \pm 0.3$ & $1.0 \pm 0.6$ & $1.6 \pm 0.3$ & $1 \pm 0.6$ & $2.6 \pm 0.33$ & $7.3 \pm 1.4^{*}$ \\
\hline & $\mathrm{F}$ & 10 & $0.6 \pm 0.3$ & $1 \pm 0.0$ & $2.3 \pm 0.3$ & $0.0 \pm 0.0$ & $0.0 \pm 0.0$ & $1.3 \pm 0.3$ \\
\hline & $\mathrm{P}$ & 10 & $0.0 \pm 0.0$ & $1 \pm 0.6$ & $2.3 \pm 1.4$ & $0.0 \pm 0.0$ & $1.3 \pm 0.3$ & $2.0 \pm 0.5$ \\
\hline Permethrin $(2.0 \mathrm{mg} /$ disc $)$ & - & 10 & $7.6 \pm 0.3^{*}$ & $8.3 \pm 0.4^{*}$ & $10 \pm 0.0^{*}$ & $8.0 \pm 0.6^{*}$ & $9.0 \pm 0.5^{*}$ & $10 \pm 0.0^{*}$ \\
\hline Control disc (vehicle) & - & 10 & $0.0 \pm 0.0$ & $1.3 \pm 0.3$ & $1.3 \pm 0.3$ & $0.0 \pm 0.0$ & $1.3 \pm 0.3$ & $2.0 \pm 0.6$ \\
\hline
\end{tabular}

$¥ B=$ Bark, $L=$ leaf, $F=$ fruit, $P=$ pneumatophore; ${ }^{*}$ results are expressed as mean \pm SEM. ${ }^{*} p<0.001$ vs. control.

TABLE 3: Insecticidal activity of the SPE4 fractions of A. corniculatum, E. agallocha, and H. fomes against S. oryzae insect at $2.0 \mathrm{mg} /$ disc and their $\mathrm{LC}_{50}$.

\begin{tabular}{|c|c|c|c|c|c|c|c|}
\hline \multirow[t]{2}{*}{ Name of plant } & \multirow[t]{2}{*}{ Fraction } & \multirow{2}{*}{$\begin{array}{l}\text { No. of } \\
\text { insects }\end{array}$} & \multicolumn{3}{|c|}{$\begin{array}{c}\text { No of dead adult insects }{ }^{*} \\
\text { Days after treatment }\end{array}$} & \multirow{2}{*}{$\begin{array}{c}\% \text { of } \\
\text { mortality }\end{array}$} & \multirow{2}{*}{$\begin{array}{l}\text { Lethal concentration } 50 \%\left(\mathrm{LC}_{50}\right) \\
\mathrm{mg} / \mathrm{disc}\end{array}$} \\
\hline & & & $5^{\text {th }}$ & $10^{\text {th }}$ & $15^{\text {th }}$ & & \\
\hline $\begin{array}{l}\text { A. corniculatum (L.) } \\
\text { blanco }\end{array}$ & SPE4 & 10 & $3.7 \pm 0.3^{*}$ & $7.3 \pm 0.47$ & $9.7 \pm 0.5^{*}$ & 97 & 0.5 \\
\hline E. agallocha (L.) & SPE4 & 10 & $2.0 \pm 0.6^{*}$ & $5.3 \pm 0.5^{*}$ & $9.0 \pm 0.7^{*}$ & 90 & 1.0 \\
\hline H. fomes (buch.) & SPE4 & 10 & $2.7 \pm 0.3^{*}$ & $4.3 \pm 0.3^{*}$ & $8.0 \pm 0.6^{*}$ & 80 & 1.5 \\
\hline Pemethrin & - & 10 & $5.6 \pm 0.8^{*}$ & $6.3 \pm 1.2^{*}$ & $10 \pm 0.0^{*}$ & 100 & 0.4 \\
\hline Control (vehicle only) & - & 10 & $0.0 \pm 0.0$ & $0.7 \pm 0.3$ & $1.0 \pm 0.5$ & 10 & - \\
\hline
\end{tabular}

${ }^{*}$ Results are expressed as mean \pm SEM. ${ }^{*} p<0.001$ vs. control.

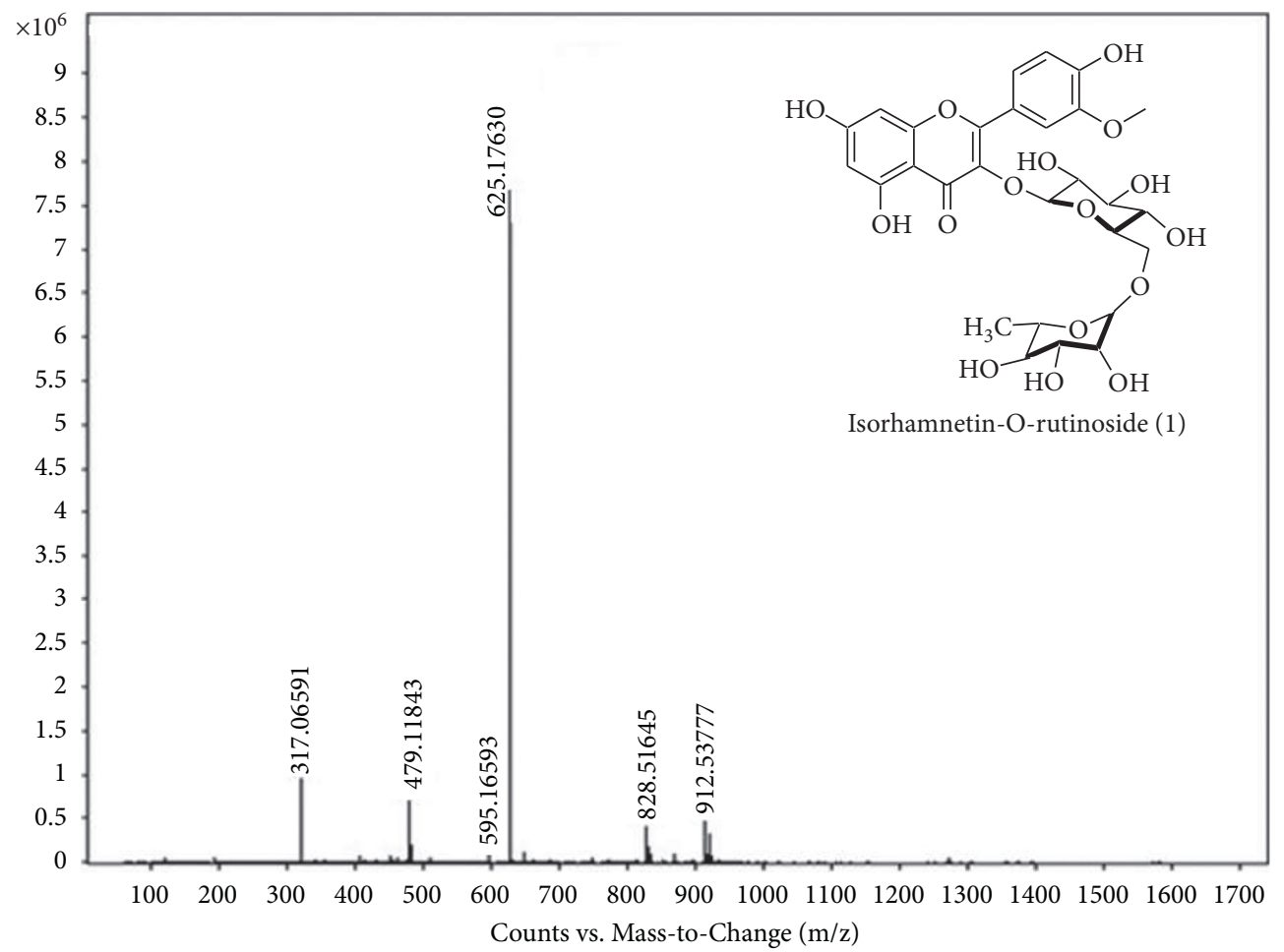

FIGURE 1: LC-ESI-MS chromatogram of a base peak $[M+H]^{+}$with $\mathrm{m} / z 625.17598$ at $6.05 \mathrm{~min}$ present in SPE4 fraction of $A$. corniculatum for the identified flavonol compound (1). 


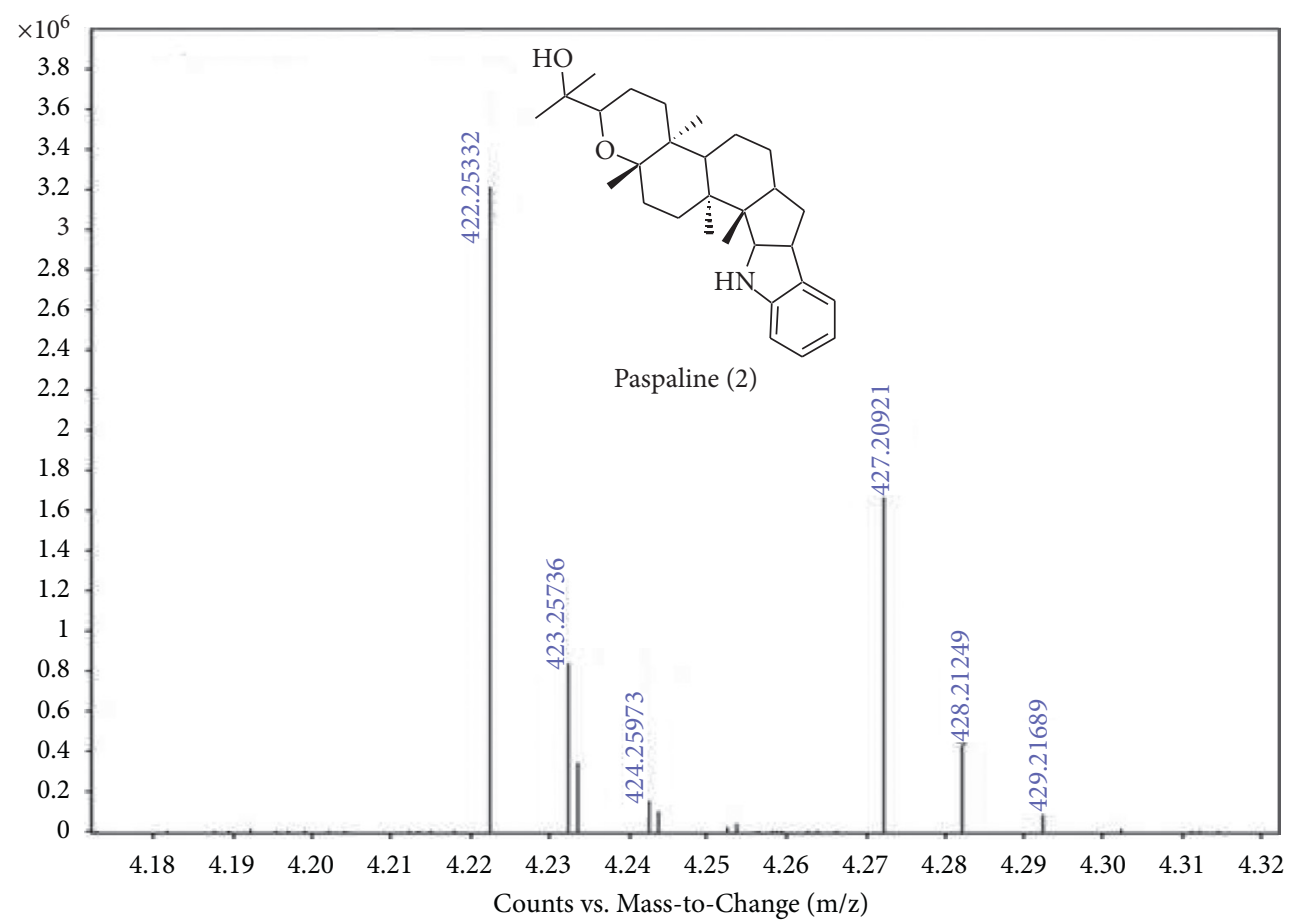

FIGURE 2: LC-ESI-MS chromatogram of a base peak $[M+H]^{+}$with $\mathrm{m} / z 422.25332$ at $7.84 \mathrm{~min}$ present in SPE4 fraction of A. corniculatum for the identified indole-diterpenoid compound (2).

\section{Discussion}

Mangrove plants grow under hostile stress conditions, and their distinctive adaptability features make them produce diverse bioactive secondary constituents that play an essential role in plant defense and survival [34]. With the aim of exploring the potential of mangrove botanical insecticides against store product pests, this is the first time we screened five Sundarban plant extracts for their toxic effect against two store product pests $S$. oryzae and S. zeamais. These store product insects are widely distributed pests that cause heavy damage by infesting grain. These insects were broadly used in the study of botanical extracts as insect repellents $[35,36]$. Insecticidal screening of all crude plant extracts at $2.5 \mathrm{mg} / \mathrm{disc}$ against the pests revealed A. corniculatum, E. agallocha, and $H$. fomes extracts were the most susceptible to both the tested pests as they showed the highest mortality. Compared to controls, an 80-100\% mortality was observed by the above three crude extracts and selected further for fractionation and bioassays $(2.0 \mathrm{mg} / \mathrm{disc})$. The solid-phase fractionation was performed to concentrate the active compounds present in the crude extracts. All the SPE fractions were tested for their toxicity against $S$. oryzae pest, and the highest bioactivity (80-97\% mortality) against the pest was mainly observed by the SPE4 (100\% MeOH) fraction for all the plant extracts. Compared to the SPE4 fractions of all these three plant extracts, the SPE4 fraction of A. corninulatum was more toxic to the $S$. oryzae with the lowest $\mathrm{LC}_{50}$ values $(0.5 \mathrm{mg} /$ disc) than other tested fractions $\left(\mathrm{LC}_{50}: 1-1.5 \mathrm{mg} / \mathrm{disc}\right)$. The mangrove plant species that are distributed around the world have economic and medicinal importance [34].
Traditional reports stated that extracts and chemicals from mangroves were commonly used as bush medicine for a long time and insecticide and piscicide activities [27]. A number of studies available on the activity of mangrove botanical extracts from A. corniculatum and E. agallocha and $H$. fomes possess antioxidant, antimicrobial, antiulcer, cytotoxic, and antitumor activities [37-40]. There was no previous insecticidal report on these plant extracts, but their bactericidal and cytotoxic activity might relate to their insecticidal activity. Plants species reported to use as fish poison could have insecticidal activity [41]. Several mangrove species have been used as fish poison [27], and among these plants, the extract from different parts of E. agallocha reported fish poison activity, which might support its insecticidal activity [37]. Furthermore, constituents with pesticidal properties have also been reported from fresh twigs and barks of A. corniculatum, E. agallocha, and Heritiera sp. that showed metabolic toxicity against different fish [27].

A number of bioactive constituents, such as polyphenols, flavonoids, triterpenes, essential oils, limonoids, coumarins, terpenoids, glycosides, and alkaloids, have been isolated from plants of mangrove origin [27,34]. It is practically difficult to specifically relate the sensitivity of the crude extract against insects as these botanical extracts generally represent a complex mixture of compounds. Some of these phytoconstituents are known to possess insecticidal activity, which could explain the observed toxicity of these plant extracts. The previous report stated that an atisane-type diterpene, ent-16 $\alpha$-hydroxy-atisane-3,4-lactone, was isolated from the bark of E. agallocha that exhibited significant antifouling activity against the adherence of Pseudomonas 
pseudoalcaligenes [42]. On the other hand, E. agallocha reported to possess phorbol ester [43], a potent insect repellent [44]. These reported constituents might be responsible for E. agallocha's insecticidal activity. H. fomes has different traditional uses other than insecticides although the plant reported to contain different polyphenolics including procyanidins [45]. Interestingly, several reports stated that polyphenol-rich extract possesses insecticidal activity [46] and this could be the case for the potent insecticidal activity of $H$. fomes.

The results of this study revealed that $A$. corniculatum bark extracts could serve as a source of potential insecticidal lead molecules as they showed the most significant insecticidal activities against both the tested pests. Therefore, the active SPE4 fraction of A. corniculatum was further analyzed by LC-MS to identify active principles responsible for its insecticidal activity. Two compounds, namely, isorhamnetin 3-O-rutinoside (1) and paspaline (2), were identified as main constituents in the active SPE4 fraction along with some unknown peaks. Compounds $\mathbf{1}$ and $\mathbf{2}$ are flavonol and indole-diterpenoid, respectively, which were previously isolated from the bark of A. corniculatum (Figures 1 and 2) $[30,32]$. Flavonols are among the most abundant natural phenolics that have strong antioxidant properties and thought to play a role in protecting plants from microorganisms, insects, and larger herbivores [47]. There was no single study on compound $\mathbf{1}$ for its insecticidal activity, but a number of studies showed that extracts containing isorhamnetin-derived flavonoids possess insecticidal activity. For example, the flower of Calendula officinalis is rich in isorhamnetin 3-O-rutinoside flavonoid and showed insecticidal activity against milk weed bugs [48]. Other reports demonstrated that $\mathrm{O}$-methyl flavonoids including isorhamnetin from Calceolaria integrifolia were the most active secondary metabolites that act as biopesticides [49]. The other identified compound paspaline (2) was an indolediterpenoid mycotoxin and was not studied before for its insecticidal activity against store product pests. However, previous toxicity investigation of compound 2 against the hemiptera (Oncopeltus fasciatus) and dipteran (Ceratitis capitata) did not find any toxicity against these pests [50]. Furthermore, A. corniculatum is reported to possess benzofuran derivatives [51], which have been reported to possess insecticidal activity [52]. However, we could not identify any benzofuran derivative in the active SPE4 fraction of A. corniculatum, rather a benzopyrano-indole derivative paspaline (2) was identified. Therefore, the insecticidal activity of $A$. corniculatum might be due to its polyphenolic constituents and could be a new source of novel biopesticides.

\section{Conclusions}

The bark extracts of Sundarban plants A. corniculatum, E. agallocha, and $H$. fomes are known to exhibit a number of therapeutic activities and are already known to have considerable medicinal importance. This study demonstrated that the botanical extracts from all these three plants showed high toxicity against the tested store product pests, especially the bark extract of $A$. corniculatum with low $\mathrm{LC}_{50}$ against S. oryzae. The active fraction of $A$. corniculatum was further studied for identification of the active compounds using LCESI-MS analysis and identified two known compounds isorhamnetin 3-O-rutinoside and paspaline as major constituents. Although these two compounds are pretty common in some medicinal plants, there is no report to date on their insecticidal activity. Therefore, the insecticidal activity of $A$. corniculatum might be due to its known constituents and could be a new source of novel biopesticides. The results of this study would be useful in promoting research aiming for the development of new biopesticides from mangrove plants, especially A. corniculatum against store product pests. Furthermore, molecular mechanistic study needs to be performed on these bioactive compounds for the development of effective natural pesticides.

\section{Data Availability}

All relevant data within this manuscript are fully available without any restriction.

\section{Conflicts of Interest}

The authors declare that they have no conflicts of interest.

\section{Authors' Contributions}

ARS, RRP, $\mathrm{CB}$, and HA contributed equally including collecting the plant materials, conducting experiments, and validating the methodology under the guidance of SJU, JAS, and RR. SN and SDS carried out HPLC-QTOF-MS analysis. SJU, JAS, and RR designed the study and helped in data analysis. SJU and LN drafted the manuscript and revised the final manuscript with the help of SDS. All the authors approved the manuscript for submission

\section{Acknowledgments}

The authors would like to thank the Khulna University Research Cell, Khulna University, and the Ministry of Science and Technology, Bangladesh, for financial support to conduct this project. Dr. Nahar gratefully acknowledges the financial support of the European Regional Development Fund-Project ENOCH (no. CZ.02.1.01/0.0/0.0/16_019/ 0000868).

\section{Supplementary Materials}

Table S1: list of collected Sundarban mangrove plants with their traditional use, reported activity, and isolated constituents. Table S2: water/methanol gradient for SPE fractionation of active methanolic crude extracts. Figure S1: GPS location of Sundarban mangrove plant collection (Kolagachia forest range, Munshiganj, Satkhira, Bangladesh) $\left(22.2152^{\circ} \mathrm{N}, 89.2376^{\circ} \mathrm{E}\right)$. Figure S2: LC-MS chromatogram of the active SPE4 subfraction of A. corniculatum. (Supplementary Materials) 


\section{References}

[1] M. B. Isman, "Challenges of pest management in the twenty first century: new tools and strategies to combat old and new foes alike," Frontiers in Agronomy, vol. 1, 2019.

[2] N. Ferry, M. G. Edwards, J. A. Gatehouse, and A. M. Gatehouse, "Plant-insect interactions: molecular approaches to insect resistance," Current Opinion in Biotechnology, vol. 15, no. 2, pp. 155-161, 2004.

[3] J. M. Pezzuto, "Plant-derived anticancer agents," Biochemical Pharmacology, vol. 53, no. 2, pp. 121-133, 1997.

[4] Y.-Z. Shu, "Recent natural products based drug development: a pharmaceutical industry perspective," Journal of Natural Products, vol. 61, no. 8, pp. 1053-1071, 1998.

[5] C. Meisner, "Report of pesticide hotspots in Bangladesh," Development Economics Research Group Infrastructure and Environment Deparment, The World Bank, Dhaka, Bangladesh, 2004.

[6] J. R. Bertomeu-Sánchez, "Introduction. Pesticides: past and present," Journal of History of Science and Technology, vol. 13, pp. 1-27, 2019.

[7] A. Cork, Q. N. Kamal, S. N. Alam, S. C. J. Choudhury, and N. S. Talekar, "Pheromones and their application to insect pest control-A Review," Bangladesh Journal of Entomology, vol. 13, pp. 1-13, 2003.

[8] M. Z. Islam, "Pheromone use for insect control: present status and prospect in Bangladesh," International Journal of Agricultural Research, Innovation and Technology, vol. 2, pp. 4755, 2012.

[9] S. H. Zahm, M. H. Ward, and A. Blair, "Pesticides and cancer," in Occupational Medicine: State of the Art ReviewsHanley and Belfus, Inc., Philadelphia, PA, USA, 1997.

[10] P. Nicolopoulou-Stamati, S. Maipas, C. Kotampasi, P. Stamatis, and L. Hens, "Chemical pesticides and human health: the urgent need for a new concept in agriculture," Frontiers in Public Health, vol. 4, p. 148, 2016.

[11] B. Singh and M. Gupta, "Pattern of use of personal protective equipments and measures during application of pesticides by agricultural workers in a rural area of Ahmednagar district, India," Indian Journal of Occupational and Environmental Medicine, vol. 13, no. 3, pp. 127-130, 2009.

[12] S.-I. Kim, J.-Y. Roh, D.-H. Kim, H.-S. Lee, and Y.-J. Ahn, "Insecticidal activities of aromatic plant extracts and essential oils against Sitophilus oryzae and Callosobruchus chinensis," Journal of Stored Products Research, vol. 39, no. 3, pp. 293303, 2003.

[13] S. Dev and O. Koul, Insecticides of Natural Origin, Harwood Academic, New York, NY, USA, 1997.

[14] M. D. Moreira, M. C. Picanço, L. C. d. A. Barbosa et al., "Plant compounds insecticide activity against Coleoptera pests of stored products," Pesquisa Agropecuária Brasileira, vol. 42, no. 7, pp. 909-915, 2007.

[15] S. Quiroz, C. L. Cespedes, J. B. Alderete, and J. Alarcon, "Ceanothane and oleanane-type triterpenes from Talguenea quinquenervia have insecticidal activity against Cydia pomonella, Tenebrio molitor and Drosophila melanogaster," Industrial Crops and Products, vol. 74, pp. 759-766, 2015.

[16] H. P. Chen, K. Yang, C. X. You, N. Lei, R. Q. Sun, and Z. F. Geng, "Chemical constituents and insecticidal activities of the essential oil of Cinnamomum camphora leaves against Lasioderma serricorne," Journal of Chemistry, vol. 2014, Article ID 963729, 5 pages, 2014.

[17] C. You, S. Guo, W. Zhang, K. Yang, Z. Geng, and S. Du, "Identification of repellent and insecticidal constituents from
Artemisia mongolica essential oil against Lasioderma serricorne," Journal of Chemistry, vol. 2015, Article ID 549057, 7 pages, 2015.

[18] X. N. Lu, X. C. Lu, Q. Z. Liu, and Z. L. Liu, "Isolation of insecticidal constituents from the essential oil of ageratum houstonianum mill. against Liposcelis bostrychophila Badonnel," Journal of Chemistry, vol. 2014, Article ID 645687, 6 pages, 2014.

[19] W. J. Zhang, Z. Zhang, Z.-Y. Chen, J.-Y. Liang, Z. F. Geng, and S.-S. Guo, "Chemical composition of essential oils from six Zanthoxylum species and their repellent activities against two stored-product insects," Journal of Chemistry, vol. 2017, Article ID 1287362, 7 pages, 2017.

[20] S. J. Uddin, Screening of Bangladeshi medicinal plants for the isolation and structural elucidation of novel anti cancer compounds, Ph.D. Thesis, Griffith University, Queensland, Australia, 2010.

[21] A. Pramanik, S. Sengupta, and M. Bhattacharyya, "Microbial diversity and community analysis of the Sundarbans mangrove, a world heritage site," in Microbial Diversity in the Genomic Era, S. Das and H. R. Dash, Eds., Academic Press, Cambridge, MA, USA, pp. 65-76, 2019.

[22] M. Haque, M. Reza, S. Abd Rahim, P. Abdullah, R. Elfithri, and M. Mokhtar, "Behavioral change due to climate change effects accelerate tiger human conflicts: a study on Sundarbans mangrove forests, Bangladesh," International Journal of Conservation Science, vol. 6, 2015.

[23] M. S. Islam, "How worthy is the Sundarbans mangrove forest? An exploratory study," Environment and Natural Resources Journal, vol. 14, pp. 17-25, 2016.

[24] K. Skalicka-Wozniak, G. Kazimierz, and J. Widelski, "Plant materials in modern pharmacy and methods of their investigations," in Thin Layer Chromatography in PhytochemistryCRC Press, Boca Rato, FL, USA, 2008.

[25] O. Boussaada, M. B. H. Kamel, S. Ammar, D. Haouas, Z. Mighri, and A. N. Helal, "Insecticidal activity of some Asteraceae plant extracts against Tribolium confusum," Bulletin of Insectology, vol. 61, pp. 283-289, 2008.

[26] J. M. Kabaru and L. Gichia, "Insecticidal activity of extracts derived from different parts of the mangrove tree Rhizophora mucronata (Rhizophoraceae) Lam. against three arthropods," African Journal of Science and Technology, vol. 2, pp. 44-49, 2001.

[27] W. M. Bandaranayake, "Traditional and medicinal uses of mangroves," Mangroves and Salt Marshes, vol. 2, no. 3, pp. 133-148, 1998.

[28] M. Afroz, S. Akter, A. Ahmed et al., "Ethnobotany and antimicrobial peptides from plants of the solanaceae family: an update and future prospects," Frontiers in Pharmacology, vol. 11, p. 565, 2020.

[29] S. Khan, C. N. T. Taning, E. Bonneure, S. Mangelinckx, G. Smagghe, and M. M. Shah, "Insecticidal activity of plantderived extracts against different economically important pest insects," Phytoparasitica, vol. 45, no. 1, pp. 113-124, 2017.

[30] D. Zhang, J. Wu, S. Zhang, and J. Huang, "Oleanane triterpenes from Aegiceras corniculatum," Fitoterapia, vol. 76, no. 1, pp. 131-133, 2005.

[31] R. Arimboor and C. Arumughan, "HPLC-DAD-MS/MS profiling of antioxidant flavonoid glycosides in sea buckthorn (Hippophae rhamnoidesL.) seeds," International Journal of Food Sciences \& Nutrition, vol. 63, no. 6, pp. 730-738, 2012.

[32] K. Rajeswari and B. Tadiboina, "Aegiceras corniculatum linn (Myrsinaceae)," Journal of Chemical and Pharmaceutical Research, vol. 7, pp. 305-316, 2015. 
[33] M. Xu, G. Gessner, I. Groth et al., "Shearinines D-K, new indole triterpenoids from an endophytic Penicillium sp. (strain HKI0459) with blocking activity on large-conductance calcium-activated potassium channels," Tetrahedron, vol. 63, no. 2, pp. 435-444, 2007.

[34] D. Nilesh Lakshman, S. Ankush Ashok, and K. Kundan, "Mangrove plants as a source of bioactive compounds: a review," The Natural Products Journal, vol. 9, pp. 86-97, 2019.

[35] O. Campolo, G. Giunti, A. Russo, V. Palmeri, and L. Zappalà, "Essential oils in stored product insect pest control," Journal of Food Quality, vol. 2018, Article ID 6906105, 2018.

[36] P. L. Soujanya, J. C. Sekhar, P. Kumar, N. Sunil, C. V. Prasad, and U. V. Mallavadhani, "Potentiality of botanical agents for the management of post harvest insects of maize: a review," Journal of Food Science \& Technology, vol. 53, no. 5, pp. 2169-2184, 2016.

[37] S. Mondal, D. Ghosh, and K. Ramakrishna, "A complete profile on blind-your-eye mangrove Excoecaria agallocha L. (Euphorbiaceae): ethnobotany, phytochemistry, and pharmacological aspects," Pharmacognosy Reviews, vol. 10, no. 20, p. 123, 2016.

[38] G. Agoramoorthy, M. Chandrasekaran, V. Venkatesalu, and M. J. Hsu, "Antibacterial and antifungal activities of fatty acid methyl esters of the blind-your-eye mangrove from India," Brazilian Journal of Microbiology, vol. 38, no. 4, pp. 739-742, 2007.

[39] D. L. De La Cruz, A. A. Gomez, E. D. Gomez, D. H. Miles, G. J. B. Cajipe, and V. P. Chavez, "Toxicants from mangrove plants: bioassay of crude extract," Journal of Ecology and Environmental Sciences, vol. 10, pp. 1-9, 1984.

[40] I. Mahmud, M. K. Islam, S. Saha, A. K. Barman, M. M. Rahman, M. Anisuzzman et al., "Pharmacological and ethnomedicinal overview of Heritiera fomes: future prospects," Int Schol Res Notices, vol. 2014, Article ID 938543, 2014.

[41] F. Tattersfield, J. T. Martin, and F. N. Howes, "Some fishpoison plants and their insecticidal properties," Bulletin of Miscellaneous Information, vol. 1940, no. 5, pp. 169-180, 1940.

[42] Z. C. Wang, Y. M. Lin, D. Q. Feng et al., "A new atisane-type diterpene from the bark of the mangrove plant Excoecaria agallocha," Molecules, vol. 14, no. 1, pp. 414-422, 2009.

[43] A. Simlai and A. Roy, "Biological activities and chemical constituents of some mangrove species from Sundarban estuary: an overview," Pharmacognosy Reviews, vol. 7, pp. 170-178, 2013.

[44] A. Ratnadass and M. Wink, "The phorbol ester fraction from jatropha curcas seed oil: potential and limits for crop protection against insect pests," International Journal of Molecular Sciences, vol. 13, no. 12, pp. 16157-16171, 2012.

[45] H. Wangensteen, H. C. Dang, S. J. Uddin, M. Alamgir, and K. E. Malterud, "Antioxidant and antimicrobial effects of the mangrove tree Heritiera fomes," Natural product communications, vol. 4, no. 3, pp. 371-376, 2009.

[46] M. S. Hashim and K. S. Devi, "Insecticidal action of the polyphenolic rich fractions from the stem bark of Streblus asper on Dysdercus cingulatus," Fitoterapia, vol. 74, no. 7-8, pp. 670-676, 2003.

[47] F. Rehman, F. Khan, and S. Badruddin, "Role of phenolics in plant defense against insect herbivory," in Chemistry of Phytopotentials: Health, Energy and Environmental Perspectives, M. M. Srivastava, L. D. Khemani, and S. Srivastava, Eds., p. 382, Springer-Verlag Berlin, Heidelberg, Germany,, 2012.

[48] B. P. BP Muley, S. S. Khadabadi, and N. B. Banarase, "Phytochemical constituents and pharmacological activities of
Calendula officinalis linn (asteraceae): a review," Tropical Journal of Pharmaceutical Research, vol. 8, pp. 455-465, 2009.

[49] C. L. Céspedes, J. R. Salazar, A. Ariza-Castolo et al., "Biopesticides from plants: Calceolaria integrifolia s.l," Environmental Research, vol. 132, pp. 391-406, 2014.

[50] M. C. González, C. Lull, P. Moya, I. Ayala, J. Primo, and E. Primo Yúfera, "Insecticidal activity of penitrems, including penitrem G, a new member of the family isolated from Penicillium crustosum," Journal of Agricultural and Food Chemistry, vol. 51, pp. 2156-2160, 2003.

[51] G. Zhang, S. Sun, T. Zhu et al., "Antiviral isoindolone derivatives from an endophytic fungus Emericella sp. associated with Aegiceras corniculatum," Phytochemistry, vol. 72, no. 1112, pp. 1436-1442, 2011.

[52] P. Proksch, M. Proksch, G. H. N. Towers, and E. Rodriguez, "Phototoxic and insecticidal activities of chromenes and benzofurans from encelia," Journal of Natural Products, vol. 46, no. 3, pp. 331-334, 1983. 